Spillovers and substitutability in production

Kerry L. Papps

Alex Bryson

Department of Quantitative Social Science Working Paper No. 19-02

April 2019 


\section{Disclaimer}

Any opinions expressed here are those of the author(s) and not those of the UCL Institute of Education. Research published in this series may include views on policy, but the institute itself takes no institutional policy positions.

DoQSS Workings Papers often represent preliminary work and are circulated to encourage discussion. Citation of such a paper should account for its provisional character. A revised version may be available directly from the author.

Department of Quantitative Social Science, UCL Institute of Education, University College London, 20 Bedford Way, London WC1H 0AL, UK 


\title{
Spillovers and substitutability in production
}

\author{
Kerry L. Papps ${ }^{1}$ and Alex Bryson ${ }^{2}$
}

\begin{abstract}
Can the existence of positive productivity spillovers between co-workers be explained by the presence of complementarities in a firm's production function? A simple model demonstrates that this is possible when workers perform their tasks sequentially and part of individuals' pay is determined by the firm's output, but also that negative spillovers may arise when workers can raise overall output unilaterally. Data from major league baseball support these predictions. They show that the pairs of players who are most complementary in the production process exert the largest positive spillovers on each other, but that negative spillovers predominate between all player pairs.
\end{abstract}

JEL Codes: J0, M5

Keywords: productivity; spillovers; baseball.

Contact Details: Alex Bryson (a.bryson@ucl.ac.uk), University College London, National Institute of Social and Economic Research and Institute for the Study of Labor

Acknowledgements: The authors would like to thank participants at the 2016 European Association of Labour Economists, 2017 Royal Economic Society and 2017 Society of Labor Economists meetings and at seminars at the Universities of Western Australia, Bristol, Cardiff and Reading and the Tinbergen Institute Amsterdam for their suggestions.

\footnotetext{
${ }^{1}$ University of Bath and IZA, Bonn

${ }^{2}$ University College London
} 


\title{
Spillovers and substitutability in production
}

\author{
"But here you are in the ninth / Two men out and three men on / \\ Nowhere to look but inside / Where we all respond to pressure." \\ BILLY JOEL, "Pressure" (1982)
}

\section{Introduction}

The possibility that a worker may become more productive as a result of working alongside a highly able co-worker can have big consequences for employers. Most workplaces involve teams and the job of any good manager is to assign workers in a way that maximises overall production. However, there are a number of reasons why performance spillovers may exist within teams, all of which imply different optimal policies for firms. Workers may learn valuable skills from each other. Workers may motivate each other, either by fostering a sense of competition or by exerting pressure on workers who underperform. Finally, it is possible that workers may care directly about their firm's overall level of output (or profits). In this case, positive spillovers will arise, provided there are complementarities in the firm's production function, meaning that workers must all perform well in order to raise output. The aim of this paper is to focus on this final channel and to examine the exact mechanism by which teammates influence each other.

The interactions between hitters in professional baseball provides an ideal setting in which to study the existence and magnitude of spillovers between teammates. Not only do accurate performance data exist at the individual level, but because hitters in baseball appear sequentially, in a fixed order (the batting 'line-up'), it is possible to isolate the causal effect of one player on the player who bats next, thereby avoiding the reflection problem (Manski 1993). Furthermore, other than by hitting a home run, the only way hitters can generate runs (and thus raise the team's probability of winning a game and making the post-season) is by acting together. For example, if three consecutive players each hit singles (that is, each is able to reach first base), the first player will in most cases, be able to circle all bases and score a run. However, if any one of the three players involved in this sequence fails in his task, the run will not be scored. By reaching first base, the first hitter therefore raises the pay-off to the second hitter of getting a hit.

The paper makes three main contributions to the literature on peer spillovers. Firstly, by using data on each plate appearance during a baseball game, we are able to identify the effect teammates have on each other from the changes in their output over 
the course of a game. Previous studies have identified productivity spillovers by exploiting exogenous changes in the composition of a person's teammates. However, the presence of relevant person-specific characteristics that are correlated with innate ability, such as age, might introduce bias into such estimates. In contrast, our study exploits changes in a given teammate's output over time. Secondly, since it is clear how hitters combine to produce runs, we can calculate the elasticity of complementarity between any pair of hitters and examine how this affects the size and direction of spillovers. Finally, we are able to distinguish the positive spillovers that arise when players raise the pay-off to each other's effort, due to complementarities in the production function, from the negative spillovers that result when one player's success creates an incentive for his teammates to free ride because they are substitutes in production.

Our findings suggest that players are highly prone to free riding, but are much less responsive to incentives to raise effort when their teammates are successful at their tasks. Positive spillovers are found to be largest between pairs of players who are the most highly complementary in the production process. However, for all players, the incentive to free-ride dominates, leading to negative overall spillovers. Paying a higher base salary or individual bonuses reduces a player's responsiveness to the returns to effort.

Although a baseball team is an atypical employer, our results are nonetheless likely to have relevance to the wider labour market. Workers - be they assembly line workers or software engineers - are often required to perform tasks with colleagues, sometimes in sequence, some of which require a great deal of interaction and some of which do not. In this case, knowledge of the nature of the joint task performed and of the way in which workers respond to incentives may prove crucial in predicting the extent to which spillovers occur. Furthermore, like all workers, baseball players can manipulate their output levels by expending more or less effort. Here, "effort" refers to concentration or mental preparation, rather than physical exertion. In fact, trying harder is often thought to be counterproductive in baseball. The Hall of Fame hitter, Reggie Jackson has said (Dorfman and Kuehl 2002):

\footnotetext{
"When I want to turn it on, I have a routine I go through. I get away from the plate. I stretch, control my breathing, and slow up my heart rate. I slow up. I start towards the plate, and I imagine myself putting the 'sweet spot' in the hitting area just as the ball is getting there... It's important to me to see myself putting that bat there and not swinging it. When I visualise, I feel my approach and the contact. I remind myself to see the release and the spin on the ball. Then I 'see it' the way I'm going to see it. I don't want to try too hard or tense up."
} 


\section{Background}

Economists have explored whether productivity spillovers exist between workers in a variety of workplaces in which productivity is observable, including check-out operators (Mas and Moretti 2009), teachers (Jackson and Bruegmann 2009; Papay et al. 2016), undergraduate students (Sacerdote 2001), university scientists (Waldinger 2012), fruit pickers (Bandiera et al. 2010), clerical workers (Falk and Ichino 2006) and professional golfers (Guryan et al. 2009). Many of these find evidence of positive peerto-peer spillovers. However, it is not always clear what mechanism is responsible for this. Mas and Moretti's results are consistent with a monitoring effect - workers' output levels rise when they know they are being observed by productive colleagues. Similarly, Bandiera et al. report evidence that is consistent with social incentives between co-workers who are friends. However, other authors speculate that spillovers may be driven by learning, motivation or competition, without any clear evidence to support this.

A handful of studies explicitly attempt to determine whether peer spillovers can be explained by incentives linked to team output. These are hampered by the fact that the form of the production function itself - and hence the degree to which workers are complements or substitutes - is unobserved in each case. Steinbach and Tatsi (2018) analyse behaviour among workers in a cargo warehouse and find evidence of both positive and negative spillovers. Workers are found to free ride when their co-workers have high permanent productivity, but also to increase their output when their coworkers display high productivity during the current shift.

In the paper closest in spirit to ours, Gould and Winter (2009) use annual data from major league baseball. They find that the performance of hitters rises when they move to teams with particularly good hitters or particularly bad pitchers. They note that this is consistent with a model in which individual players are rewarded for team success. Gould and Winter find that spillovers are substantial - an increase of 0.1 in the batting average of a hitter's teammates will raise his batting average by 0.021 . A major drawback of Gould and Winter's study is that, although they attribute the spillovers they estimate to a production function, their data are too highly aggregated to establish this link and it is not possible to rule out other explanations, such as a motivation or monitoring effect.

In a more recent paper, Arcidiacono et al. (2017) use possession-level data from National Basketball Association games. Since only one player can score during each possession, they estimate a complicated production function which is a function of the 
offensive and defensive abilities of the players on the court. They conclude that performance spillovers between teammates are extremely large: a one standard deviation increase in the spillover effect of a single player increases team success by $63 \%$ as much as a one standard deviation increase in the player's own performance.

As in Arcidiacono et al. (2017), our paper uses play-by-play data to isolate the effects of players who are actually contributing to team production at any point during a given game. However, unlike in basketball, baseball players are always observed succeeding or failing during each plate appearance and, since they hit one at a time, they can observe the performance of their teammates at the time they make their effort decision. Hence, we can identify the causal effect of a single productive act by one player (getting on base) on the performance of hitters who bat later in the game. These features of the game, which are fully captured in our data, mean we can attribute any spillovers we find to the production function and associated incentives, ruling out other potential explanations.

\section{A model of team incentives}

Assume that there are only two workers at a firm, each of whom performs the same task twice, and that total output at the firm can be written:

$$
Y=\sum_{t=1}^{2} Y_{t}=\sum_{t=1}^{2}\left(\gamma_{1} y_{1 t}+\gamma_{2} y_{2 t}+\gamma_{12} y_{1 t} y_{2 t}\right)
$$

where $y_{i t}$ is worker $i$ 's performance on task $t$ and can take values 0 (failure) or 1 (success). The parameter $\gamma_{12}$ determines the extent to which the firm's output depends on both workers performing their tasks well. If $\gamma_{12}=0$, workers are perfect substitutes; if $\gamma_{12}>0$, there are complementarities in production.

An individual's probability of succeeding at his/her task contains a fixed component, $\delta$, and a component that is due to the level of effort $e$ put into the task:

$$
P\left(y_{i t}=1\right)=\delta_{i}+e_{i t} \text {. }
$$

Worker $i$ 's utility is a function of his/her wages $w$ and the level of effort put into each task and can be written:

$$
u\left(w_{i}, e_{i 1}, e_{i 2}\right)=\ln w_{i}-\pi \sum_{t=1}^{2} e_{i t}^{2} .
$$

Wages consist of a fixed component $\hat{w}$ and a component that is proportional to the firm's output, $Y$ : 
$w_{i}=\hat{w}_{i}+\phi Y$.

When $\phi>0$, there is profit sharing, so that individual pay is partly determined by the firm's output.

Suppose that during each round worker 1 performs his/her task before worker 2. In this case, worker 2 observes worker 1's output at the time he/she chooses how much effort to put in. If worker 2 wishes to maximise expected utility, his/her optimal effort in period 2 is:

$$
e_{22}=\frac{1}{2 \pi} \frac{\phi\left(\gamma_{2}+\gamma_{12} y_{12}\right)}{\hat{w}_{2}+\phi\left(Y_{1}+\gamma_{1} y_{12}\right)}
$$

Assuming profit sharing is a relatively small component of overall pay, worker 2's optimal effort in period 1 can be written as:

$$
e_{21}=\frac{1}{2 \pi} \frac{\phi\left(\gamma_{2}+\gamma_{12} y_{11}\right)+E_{21}\left(\phi Y_{2} \mid y_{21}=1\right)-E_{21}\left(\phi Y_{2} \mid y_{21}=0\right)}{\hat{w}_{2}+\phi \gamma_{1} y_{11}+E_{21}\left(\phi Y_{2} \mid y_{21}=0\right)},
$$

where $E_{i t}(\cdot)$ denotes the expectation of worker $i$ in period $t$.

When $\phi=0$ (so that there is no profit sharing), the worker's effort level is unaffected by his/her co-worker's output, regardless of the nature of the firm's production function. ${ }^{3}$ When $\phi>0$, effort is affected by the output of the co-worker, but the direction of the spillover depends on the nature of the production function. If $\gamma_{12}=0$, negative spillovers exist. If $\gamma_{12}>0$, positive spillovers may exist, provided that $\gamma_{12}$ is large enough relative to $\gamma_{2}$.

Worker 1 cannot observe worker 2's performance each period, so his/her optimal performance in period 2 is:

$e_{12}=\frac{1}{2 \pi} \frac{E_{12}\left(\phi Y_{2} \mid y_{12}=1\right)-E_{12}\left(\phi Y_{2} \mid y_{12}=0\right)}{\hat{w}_{1}+\phi Y_{1}+E_{12}\left(\phi Y_{2} \mid y_{12}=0\right)}$,

and his/her optimal effort in period 1 is:

$e_{11}=\frac{1}{2 \pi} \frac{E_{11}\left(\phi\left(Y_{1}+Y_{2}\right) \mid y_{11}=1\right)-E_{11}\left(\phi\left(Y_{1}+Y_{2}\right) \mid y_{11}=0\right)}{\hat{w}_{2}+E_{11}\left(\phi\left(Y_{1}+Y_{2}\right) \mid y_{11}=0\right)}$.

Define $Y_{i t}^{0}$ as the expected firm output that arises if worker $i$ fails on his/her task in period $t$ and $\Delta Y_{i t}$ as the expected change in firm output from this that will result if

\footnotetext{
${ }^{3}$ Hence, we are ruling out the possibility that workers learn from or exert social pressure on each other, which is reasonable since our focus is on variation from $t=1$ to $t=2, e . g$. from product to product (or customer to customer) over the course of a working day.
} 
worker $i$ succeeds in period $t$. Equations 5-8 can then be combined with equation 2 to yield:

$$
P\left(y_{i t}=1\right)=\frac{1}{2 \pi} \frac{\phi \Delta Y_{i t}}{\hat{w}_{i}+\phi Y_{i t}^{0}}+\delta_{i} .
$$

Equation 9 can be linearised by taking a first-order Taylor expansion around the average values of $Y^{0}, \Delta Y$ and $\hat{w}$ (denoted $Y^{0}, \overline{\Delta Y}$ and $\overline{\hat{w}}$, respectively):

$$
P\left(y_{i t}=1\right)=\frac{2 \pi \phi}{\overline{\hat{w}}+\phi \overline{Y^{0}}}+\frac{1}{2 \pi} \frac{\phi}{\overline{\hat{\hat{w}}}+\phi \overline{Y^{0}}} \Delta Y_{i t}-\frac{2 \pi \phi^{2}}{\left(\overline{\hat{\hat{w}}}+\phi \overline{Y^{0}}\right)^{2}} Y_{i t}^{0}-\frac{2 \pi \phi}{\left(\overline{\hat{\hat{w}}}+\phi \overline{Y^{0}}\right)^{2}} \hat{w}_{i}+\delta_{i} .
$$

Worker 1 can affect worker 2's probability of success in the same period by raising the firm's output, $Y_{i t}^{0}$, (which will lower worker 2's probability of success) or by raising the pay-off to worker 2's output, $\Delta Y_{i t}$, (which will raise worker 2's probability of success). This can be seen in the following expression:

$$
P\left(y_{2 t}=1 \mid y_{1 t}=1\right)-P\left(y_{2 t}=1 \mid y_{1 t}=0\right)=\frac{1}{2 \pi} \frac{\phi}{\overline{\hat{w}}+\phi \overline{Y^{0}}} \gamma_{12}-\frac{2 \pi \phi^{2}}{\left(\overline{\hat{w}}+\phi \overline{Y^{0}}\right)^{2}} \gamma_{1} .
$$

The presence of positive output spillovers requires the presence of both complementarities in production (so that $\gamma_{12}>0$ ) and some form of profit sharing (so that the coefficient on $\Delta Y$ is positive in equation 10). ${ }^{4}$ The former is a 'technological' effect (equal to $\gamma_{12}$ ) and the latter is an 'incentive' effect (equal to $\phi /\left(2 \pi\left(\overline{\hat{w}}+\phi \overline{Y^{0}}\right)\right)$ ) and the overall spillover effect is equal to the product of the two. The second term on the right-hand side of equation 11 will introduce a negative spillover, which is not due to complementarities in production, but rather to the fact that worker 2 may free ride on the effort of worker 1 when they are substitutable to some degree.

Because worker 2 performs his/her task second, he/she can only affect worker 1's output in period 2 and then only by raising the firm's output in period 1 (which will unambiguously lower worker 1's probability of success).

\section{Data}

The primary data are collected from www.retrosheet.org, which contains complete game logs for all major league baseball games since 1930. These are used to construct play-by-play data on all regular season major league games from 1998 (when the league

\footnotetext{
${ }^{4}$ Indeed, Kinsler (2016) found that complementarities between primary school teachers were extremely small in a setting where teachers' pay was not tied to the overall performance of students.
} 
expanded to 30 teams) to 2013, comprising over 2 million observations on individual plate appearances. The data record who was hitting, who was pitching and what the outcome of the plate appearance was. This study simply focuses on whether a hitter reached base, that is, whether he achieved a hit or a walk or was hit by a pitch.

In addition, data on whether a player's contract specified any type of bonus for individual performance (such as additional pay for being selected for the annual AllStar Game or for attaining a certain batting average) were obtained from the Cot's Baseball Contracts website (www.mlbcontracts.blogspot.com) for each season from 2005 to 2010.5 Players' annual salaries were taken from Sean Lahman's Baseball Archive (available from www.baseball1.com) for each season from 1998 to 2013. These were adjusted for inflation using the Consumer Price Index and expressed in 2010 dollars.

Players receive team bonus payments if their team qualifies for the post-season by having the best record in one of the six divisions at the end of the regular season, or else has the best (or since 2012, one of the two best) records in each of the two leagues (the National League and the American League). The amount of these payments depends on how far a team progresses in the post-season. Each year, a certain amount of money is allocated to the World Series champions and the teams that lose at each stage of the post-season. It is up to a team how they divide this between their players, although it most cases it is equally shared between all the players who contributed to the team's success during the season. ${ }^{6}$ Hence, in addition to a player's natural instinct to make the post-season, he has a financial incentive to do so.

Table 1 presents descriptive statistics for the key variables. On average, a hitter is successful in getting on base during around a third of plate appearances. The average salary is around $\$ 1.9$ million; however, there is substantial variation in this over players' careers (Papps 2019). About 30\% of players are paid some form of individual performance bonus.

\section{Reduced form estimation}

\footnotetext{
5 The Cot's Contracts data are largely based on information from the Associated Press and local newspapers covering individual clubs. Sports Illustrated Interactive described it as "the unofficial clearinghouse for MLB contracts" and "the most reliable public source" on baseball contract data (Donovan 2008).

${ }^{6}$ For example, in 2013, players for the World Series champions, Boston Red Sox, voted to share the total bonus pool equally between 58 players, which was worth $\$ 307,323$ per player. Although this is a relatively small amount for star players, it represents a substantial bonus for players earning the league minimum salary of $\$ 490,000$.
} 
For comparison purposes, the analysis begins by using annual data and Gould and Winter's (2009) preferred specification, whereby player $i$ 's batting average in season $y$, $B A$, is regressed on the collective batting average of his teammates on team $s$ that season, $\overline{B A}$ :

$B A_{i y}=\varsigma \overline{B A}_{i y}+\mu_{i}+\lambda_{s(i, y)}+\psi_{y}+u_{i y}$

where $\mu, \lambda$ and $\psi$ are player, team and season fixed effects, respectively.

As seen in the first column of Table 2, a spillover elasticity of 0.134 is found, not dissimilar to the value of 0.214 obtained by Gould and Winter. However, batting average is the wrong measure of individual success in this setting, because if spillovers are driven by joint production, hitters should only care whether their teammates are on base, not how they got there. In other words, it should not matter whether a player's teammates got an equal number of hits or walks. When teammates' batting average is replaced by teammates' on-base percentage (in the second column), the spillover is almost halved. The elasticity falls further when player $i$ 's on-base percentage is used as the dependent variable.

A further problem with this specification is that if joint production matters, players should only care about the on-base percentage of those players whom they appear alongside, not players on the roster who never appear in the same games. To correct for this, the collective on-base percentage was replaced by the average fraction of player $i$ 's teammates who got on base during their most recent plate appearance, calculated across all of player $i$ 's plate appearances in season $y$. This results in a substantial drop in the spillover elasticity (as seen in the fourth column of Table 2) and it is no longer significant. Hence, a large part of the spillovers identified by Gould and Winter appears to be driven by some mechanism other than joint production, perhaps intra-team competition for starting positions or the ability of teams with "deep" rosters to rest their top players during the season.

The play-by-play data afford a much better test of the joint production hypothesis than do the annual data, since they allow us to observe how successful a person's teammates have been at the time he is making every effort decision during a season, as well as any other relevant prevailing factors at that point in time. For this reason, in the first column of Table 3, a dummy for whether player $i$ got on base during his $t$ th plate appearance is regressed on the fraction of his teammates who got on base during their most recent plate appearance, as follows:

$O N B A S E_{i t}=\varsigma \overline{O N B A S E}_{i t}+\mathbf{X}_{i t} \boldsymbol{\varphi}+\mu_{i}+u_{i t}$, 
Here, $\mathbf{X}$ includes a full set of dummies for innings number, to control for general fatigue on the part of the hitter or pitcher, and a full set of dummies for the opposing pitcher, to account for variation in the quality of pitching that a hitter faces. Player fixed effects are included to control for differences in inherent ability across hitters.

The estimated spillover elasticity is slightly lower than in the final column of Table 2 ; however, because of the vastly larger sample size, it is now highly significant. The results imply that a $10 \%$ increase in the fraction of a person's teammates getting on base raises the person's probability of getting on base by $0.2 \%$.

In the second column of Table 3, player-game fixed effects are used in place of the player fixed effects. This means that the model is identified solely by changes in $\overline{O N B A S E}$ over the course of a game. This controls for the choice of hitting line-up made by managers at the start of each game, which is almost certain to be related to players' relative performances at that point in time. This makes relatively little difference to the estimated spillover elasticity.

In the final column of Table 3, dummies for whether each teammate got on base during his most recent plate appearance are added in place of $\overline{O N B A S E}$, as follows:

$$
O N B A S E_{i t}=\sum_{j=1}^{8} \varphi_{j} O N B A S E_{i t}^{j}+\mathbf{X}_{i t} \boldsymbol{\chi}+\mu_{i}+u_{i t},
$$

The results of estimating equation 14 are presented in the final column of Table 3 . The coefficients on the teammate dummies add together to give the same coefficient as in the second column. However, they allow us to determine which teammates are most important. The results suggest that the size of the spillovers falls with the number of positions between players in the line-up, except that a player has an insignificant effect on the hitter who immediately follows him in the line-up.

None of the results in this section accurately measure whether spillovers are due to joint production, because they do not control for the incentives facing a player at each point in time. The next section addresses this, by following closely the model from Section 3.

\section{Two-stage estimation}

Taking the probability of making the post-season in a given season as the measure of team output, the model outlined in Section 3 predicts that a player's performance at any point during a game will be a function of his team's probability of making the postseason if he fails to get on base and of the difference he can make to this probability by 
getting on base ( $Y^{0}$ and $\Delta Y$ in the notation of the model, respectively). This section of the analysis will consist of two stages. In the first, the universe of play-by-play data will be used to calculate the post-season probabilities. In the second, these probabilities will be added to a performance equation.

\section{Production effect}

For each plate appearance, two variables are calculated, reflecting the incentives the hitter faces at that point in time. The first is the baseline post-season probability, $P S P R O B^{0}$, which is the probability of the player's team making the post-season if he fails to get on base. The second variable is the change in the team's probability of making the post-season that results from the player getting on base, $\triangle P S P R O B$. These are analogous to $Y^{0}$ and $\Delta Y$, respectively.

To construct these variables, first the proportion of occasions on which a team ends up winning a game when a hitter fails to get on base, $P(W I N=1 \mid O N B A S E=0)$, is calculated for each combination of relative score (i.e. home team runs minus away team runs), inning number, number of outs during the current inning, and number of base runners. $^{7}$ The proportion of occasions on which a team ends up making the post-season when it loses a game, $P(P S=1 \mid W I N=0)$, is then calculated, within each combination of games behind the division-leading team and number of games left in the season. ${ }^{8}$ $P(W I N=1 \mid O N B A S E=1)$ and $P(P S=1 \mid W I N=1)$ are calculated in the same manner.

The baseline post-season probability can then be calculated as follows:

$$
\begin{aligned}
& \operatorname{PSPROB}^{0}=(P(P S=1 \mid W I N=1)-P(P S=1 \mid W I N=0)) P(W I N=1 \mid \text { ONBASE }=0) \\
& +P(P S=1 \mid W I N=0),
\end{aligned}
$$

and the difference in post-season probability as:

$$
\begin{aligned}
\triangle P S P R O B=( & P(P S=1 \mid W I N=1)-P(P S=1 \mid W I N=0)) \\
& \times(P(W I N=1 \mid \text { ONBASE =1) }-P(\text { WIN =1|ONBASE =0) }) .
\end{aligned}
$$

A hitter's average baseline post-season probability is close to the value of 0.267 that would be expected, given that 8 out of 30 teams made the post-season each year during the sample period, and the difference in post-season probability is also positive, as seen in Table 1. The latter is small relative to the former and indicates that, on

\footnotetext{
${ }^{7}$ Relative score is censored at -5 and 5 and the number of innings is censored at 10 .

${ }^{8}$ Games behind is censored at 10 and the number of games left in the season is split into four equal-sized categories (0-40 games, 41-81 games, 82-122 games and 123-163 games).
} 
average, a hitter can raise his team's likelihood of making the post-season by 0.7 percentage points by getting on base. However, there is substantial variation in both these variables. The difference in post-season probability is even negative in some highly unlikely scenarios. Figure 1 illustrates how the averages of the two post-season probability variables vary by the circumstances of a game and season. Neither the baseline post-season probability nor the difference in post-season probability vary much by the number of outs during the inning at the time the player comes to bat, the number of innings that have been played (other than during games that go to extra innings) or the number of games remaining in the season. However, both the baseline post-season probability and the difference in post-season probability are higher when more runners are on base or a team is fewer games behind the leading team in its division. In addition, not surprisingly, the baseline post-season probability is higher the larger the lead a team has at the time a player comes to the plate and the difference in post-season probability is highest when the hitter's team is losing by one run.

The patterns in Figure 1 imply that a hitter's teammates may influence the postseason probabilities he faces either by getting on base or by batting in a run and thereby changing the relative score. In the first column of Table $4, P S P R O B^{0}$ is regressed on a set of dummies for whether each of the other hitters in the line-up reached base during his last plate appearance. ${ }^{9}$ An important issue is the fact that the choice of hitters - and the order in which they bat - is endogenously determined by a team's manager prior to each game. If a manager is effective, then the best available players will be chosen to start games which are expected to be close, meaning that there may be selection bias. To eliminate this possibility, the analysis focuses solely on how a player's performance varies from plate appearance to plate appearance within a game, as follows:

$$
\operatorname{PSPROB}_{i t}^{0}=\sum_{j=1}^{8} \phi_{j} O N B A S E_{i t}^{j}+\mathbf{X}_{i t} \boldsymbol{\delta}+u_{i t},
$$

where $i$ is a team-game combination and $t$ is a particular plate appearance within a game, $O N B A S E^{j}$ is a dummy for whether the $j$ th hitter before the reference player got on base, and $\mathbf{X}$ is a vector of control variables, consisting of a full set of dummies for innings number.

These coefficients (which are illustrated in Figure 2) indicate that the effect of each of a hitter's teammates on his level of $P S P R O B^{0}$ are positive and roughly equal. A

\footnotetext{
${ }^{9}$ There are nine hitters on a baseball team. The first plate appearance for each hitter during each game is dropped, because at that point, not all hitters have entered the game.
} 
similar exercise is undertaken for $\triangle P S P R O B$ in the first column of Table 5. The coefficients (also plotted in Figure 2) indicate that the effect of the preceding hitter in the line up on $\triangle P S P R O B$ is significant and positive; however, the coefficient declines the further back in the line-up a hitter is and is negative for players more than three places earlier in the line-up.

Unlike in the model presented in Section 3, there are nine hitters in a line-up. The specifications in the first columns of Tables 4 and 5 are appropriate if a team's probability of success is only determined by the interactions of each pair of player onbase dummies. However, as noted in the introduction, in many cases three or more hitters must succeed in getting on base in order to score a run. In this case, the production function would include interactions between three or more player dummies. To examine this, the second columns of Tables 4 and 5 add a full set of two-way interactions between the team-mate on-base dummies, which would be appropriate if the production function includes only two-way and three-way interactions between the player performance dummies. This makes little difference to the effect each team-mate has on a player's performance, holding other team-mates' performance at their averages. Adding three-way interactions (in the third columns of Tables 4 and 5) similarly has little effect.

\section{Incentive effect}

The model of Section 3 implies that if players expend the optimal level of effort, their performance will be affected by the probability of their team winning, $P S P R O B^{0}$, and the amount by which their performance raises this probability, $\triangle P S P R O B$. Therefore, these are added to equation 14 . The identification strategy requires that there not be any correlation in the ease of getting on base between successive hitters. The inclusion of pitcher dummies controls for the differences in pitching quality caused by pitching substitutions made by the opposing manager during a game. However, there are a number of other possible reasons why this might not be the case. One possibility is that as pitchers start to tire, their performance levels will deteriorate from at-bat to at-bat. However, by leaving the full set of teammate on-base dummies in the estimation equation alongside $P S P R O B^{0}$ and $\triangle P S P R O B$, we control for the baseline likelihood of getting on base at any point during the game.

Endogeneity may also arise if pitchers - as well as hitters - respond to incentives. As a consequence, the equivalents of $P S P R O B^{0}$ and $\triangle P S P R O B$ for each opposing pitcher - OPPPSPROB ${ }^{0}$ and $\triangle O P P P S P R O B$ - are calculated and are added alongside 
the hitter's values. Since opposing teams have different probabilities of making the post-season, given their performances earlier in the season, the values of the pitcher's incentive variables differ from those of the hitter.

The following specification is therefore used:

$$
\begin{aligned}
\text { ONBASE }_{i t}=\alpha \Delta \operatorname{PSPROB}_{i t}+\beta P S P R O B_{i t}^{0} & \gamma \Delta \operatorname{OPPPSPROB}_{i t}+\delta O P P P S P R O B_{i t}^{0} \\
& +\sum_{j=1}^{8} \phi_{j} \text { ONBASE }_{i t}^{j}+\mathbf{X}_{i t} \boldsymbol{\gamma}+\theta_{i}+u_{i t},
\end{aligned}
$$

where $\mathbf{X}$ is the same as in equation 13. This equation is the empirical counterpart to equation 10, except that since salaries are fixed each season, focusing on within-game variation controls for the effects that salary might have on performance, i.e. the effect of $\hat{w}$ in equation 10 .

The results of estimating equation 16 are presented in the first column of Table $6 .{ }^{10}$ As implied by theory, the coefficient on $\triangle P S P R O B$ is positive and the coefficient on $P S P R O B^{0}$ is negative. Hence, players are more likely to get on base when their team has a low chance of winning the game and when doing so is likely to increase this probability by a lot. Similarly, $\triangle O P P P S P R O B$ and $O P P P S P R O B^{0}$ have negative and positive coefficients, respectively, implying that pitchers also respond to incentives. Players appear to be much more sensitive to $P S P R O B^{0}$ than to $\triangle P S P R O B$ : at the mean, the elasticity of performance with respect to $P S P R O B^{0}$ is -0.620 , whereas the elasticity with respect to $\triangle P S P R O B$ is just 0.016 .

Comparing the coefficients in Tables 4, 5 and 6, it is possible to calculate the overall size of the spillover effect operating through the joint production channel. Because different pairs of players are complementary in the production process to different degrees, this will vary by player pair, as summarised in Table 7 . The first column of the table reports the elasticity of complementarity between any two hitters in a line-up, $i$ and $j .{ }^{11}$ The second column reports the spillover elasticity - that is, the elasticity of player $i$ 's performance with respect to player $j$ 's performance - that is due

\footnotetext{
${ }^{10}$ Although $P S P R O B^{0}$ and $\triangle P S P R O B$ are generated variables, since they are calculated using the universe of observations on plate appearances, there is no need to adjust the standard errors.

${ }^{11}$ The elasticity of complementarity between two inputs is usually defined as the derivative of the log of the marginal rate of substitution with respect to the log of the ratio of the two inputs. Given the discrete nature of the inputs in this case, the elasticity of complementarity between players 1 and 2 is defined as $\left(\operatorname{MRTS}_{12}\left(y_{1}=1, y_{2}=1\right)-\operatorname{MRTS}_{12}\left(y_{1}=1, y_{2}=0\right)\right) / \operatorname{MRTS}_{12}\left(y_{1}=1, y_{2}=1\right)$, where MRTS 12 is the marginal rate of technical substitution between 1 and 2 and is equal to $\left(\gamma_{1}+\gamma_{12} y_{2}\right) /\left(\gamma_{2}+\gamma_{12} y_{1}\right)$. The elasticity is therefore equal to $\gamma_{12} / \gamma_{1}$.
} 
solely to the effect of player $j$ on $\triangle P S P R O B$. The third column reports the spillover elasticity that is due solely to the effect of player $j$ on $P S P R O B^{0}$. The final column reports the overall spillover elasticity, which is simply the sum of the elasticities in columns 2 and 3.

The effect of $P S P R O B^{0}$ dominates the effect of $\triangle P S P R O B$ for any pair of players, so that the negative spillovers that teammates produce by raising the post-season probability outweigh the positive spillovers they produce by raising the returns to effort. As a result, the overall spillover effect is always negative. However, it exhibits substantial heterogeneity and its magnitude is closely related to the elasticity of complementarity: both fall rapidly as the distance between two hitters in the line-up increases. The spillover elasticity between one player and the player who precedes him in the line-up is close to zero. However, the spillover elasticities between players who are more than four places apart in the line-up are around -0.003 .

The final row of Table 7 reports the elasticities of a given player with respect to his teammates' average performance. The overall spillover elasticity is -0.020 , compared to 0.024 in Table 3. Hence, the positive spillovers reported in the reduced form regressions (and in Gould and Winter (2009)) cannot be explained by the incentives created by the production function alone. Despite this, the presence of complementarities in production does result in positive spillovers. It is simply that the free riding effect is much stronger because players are not perfect complements. The presence of joint production leads to a positive spillover with an elasticity of 0.004 across all player pairs, but this would be 0.021 if all players were as complementary as players $i$ and $i-1$.

\section{Robustness tests}

A series of robustness tests were done. Firstly, it is possible that players whose primary role on the team is pitching will be less responsive to team incentives, either because they are unable to alter their hitting performance from plate appearance to plate appearance or because they are concentrating more on their pitching performance. As a result, equation 18 was estimated again, excluding pitchers from the sample. This was found to have little effect on the results, as seen in the second column of Table 6 .

Secondly, although the order of the batting line-up is fixed, teams are free to substitute one hitter for another during games. In particular, managers often choose to bring a specialist hitter (a 'pinch hitter') into the game when the score is particularly close. In this case, the positive coefficient on $\triangle P S P R O B$ found above may simply 
reflect an optimal choice of substitute hitter. In order to control for this source of endogeneity, the sample was restricted to observations prior to any substitutions having been made on a hitter's team. As seen in the third column of Table 6, this actually increases the coefficients on $\triangle P S P R O B$ and $P S P R O B^{0}$ slightly.

Finally, the output measure used so far - ONBASE - counts walks as a success on the part of a hitter. Although hitters can "draw a walk" by inducing the opposing pitcher to pitch poorly, in some cases a hitter may play no role in determining whether he got on base due to a walk. To test if this influences the results, whether a player got a hit was used as an alternative output measure, with all situations in which a hitter got a base on balls omitted. Once again, a positive coefficient on $\triangle P S P R O B$ and a negative coefficient on $P S P R O B^{0}$ are found, as reported in the final column of Table 6. The elasticities of getting a hit with respect to $\triangle P S P R O B$ and $P S P R O B^{0}$ are 0.014 and -0.839 , respectively.

\section{Heterogeneity in incentive effect}

So far, the estimation has assumed that spillover elasticities are homogenous across all players. However, equations 6 and 8 show that both the positive and negative spillovers should be smaller for players who are paid higher salaries, because any given team bonus will constitute a smaller component of their overall pay. By the same argument, the magnitude of spillover elasticities should be negatively related to the provision (and generosity) of individual performance bonuses, because workers will always care more about their own performance in every situation, regardless of its potential effect on team output.

To examine whether the magnitude of spillovers vary according to salary or the presence of performance-related pay, equation 18 was estimated separately for every combination of player and year. The estimated values of $\alpha$ and $\beta$ from these regressions were then used as dependent variables in the following specifications:

$$
\begin{aligned}
& \hat{\alpha}_{i y}=\varphi_{1} \text { BONUS }_{i y}+\varphi_{2} \operatorname{SALARY_{iy}}+\mathbf{A G E}_{i y} \varphi_{3}+\pi_{i}+u_{i y}, \\
& \hat{\beta}_{i y}=\varphi_{1} \text { BONUS }_{i y}+\varphi_{2} S A L A R Y_{i y}+\mathbf{A G E}_{i y} \varphi_{3}+\pi_{i}+u_{i y},
\end{aligned}
$$

where BONUS is a dummy variable indicating that a player's contract specified individual performance bonuses in year $y$ and $S A L A R Y$ is the player's real salary in year $y$.

As reported in the first column of Table 8, the coefficients on BONUS and SALARY are negative and significant in equation 19. This implies that spillover elasticities are 
lower when a person is paid an individual bonus or a higher salary. Paying an individual bonus reduces $\alpha$ by around tenfold, while the elasticity of $\alpha$ with respect to SALARY is -2.1 , suggesting that although the magnitude of the positive spillover effect is small on average, it is very sensitive to the design of a person's compensation package. Neither BONUS nor SALARY was found to have a significant effect on $\beta$ in equation 20, implying that the incentive to free ride persists, regardless of contract type.

\section{Conclusion}

We presented a simple model of team and individual performance. This implies that productivity spillovers will exist between teammates if complementarities exist in the production function and if individual pay is determined in part by team output. Workers are predicted to produce both negative spillovers, by raising team output, and positive spillovers, by raising the pay-offs to their teammates' effort.

Using play-by-play data for all major league baseball games between 1998 and 2013, we then tested the predictions of the model. For each plate appearance during a game, the probability of the hitter's team making the post-season is calculated, along with the amount by which this probability will change if the hitter gets on base. As predicted by theory, the former has a negative effect on a hitter's likelihood of getting on base and the latter has a positive effect. Since a hitter's teammates will change both probabilities depending on their performance during a game, performance spillovers arise.

Players who are closest together in the batting line-up are the most complementary in the production function and, accordingly, exert the largest positive spillovers on each other. Positive spillovers are also found to be largest among players with low base salaries and who are not paid individual performance bonuses. However, for all players the negative spillovers that arise when teammates raise team output unilaterally outweigh the positive spillovers. The small negative overall effects we find stand in contrast to other recent studies using basketball and baseball data.

Our results suggest that managers of factory assembly lines and other production processes involving sequential performance should be wary of the potential for free riding behaviour if their workers are highly substitutable. In these cases, tying individual workers' pay to team output might have the perverse effect of reducing effort levels.

\section{References}


Arcidiacono, Peter, Josh Kinsler, and Joseph Price. 2017. Productivity spillovers in team production: Evidence from professional basketball. Journal of Labor Economics 35, no. 1: 191-225.

Bandiera, Oriana, Iwan Barankay, and Imran Rasul. 2010. Social Incentives in the Workplace. Review of Economic Studies 77, no. 2: 417-458.

Dorfman, Harvey A., and Karl Kuehl. 2002. The mental game of baseball: A guide to peak performance, $3^{\text {rd }}$ edition. Lanham, MD: Diamond Communications.

Falk, Armin, and Andrea Ichino. 2006. Clean evidence on peer effects. Journal of Labor Economics 24, no. 1: 39-57.

Gould, Eric D., and Eyal Winter. 2009. Interactions between workers and the technology of production: Evidence from professional baseball. Review of Economics and Statistics 91, no. 1: 188-200.

Guryan, Jonathan, Kory Kroft, and Matthew J. Notowidigdo. 2009. Peer effects in the workplace: Evidence from random groupings in professional golf tournaments. American Economic Journal: Applied Economics 1, no. 4: 34-68.

Jackson, C. Kirabo, and Elias Bruegmann. 2009. Teaching students and teaching each other: The importance of peer learning for teachers. American Economic Journal: Applied Economics 1, no. 4: 85-108.

Kinsler, Josh. 2016. Teacher complementarities in test score production: Evidence from primary school. Journal of Labor Economics 34, no. 1: 29-61.

Manski, Charles F., 1993. Identification of endogenous social effects: The reflection problem. Review of Economic Studies 60, no. 3: 531-542.

Mas, Alexandre, and Enrico Moretti. 2009. Peers at work. American Economic Review 99, no. 1: 112-145.

Papay, John P., Eric S. Taylor, John H. Tyler, and Mary Laski. 2016. Learning job skills from colleagues at work: Evidence from a field experiment using teacher performance data. Working Paper 21986, National Bureau of Economic Research.

Papps, Kerry L. 2019. Productivity over the life cycle: Evidence from professional baseball. University of Bath.

Sacerdote, Bruce. 2001. Peer effects with random assignment: Results for Dartmouth roommates. Quarterly Journal of Economics 116, no. 2: 681-704.

Steinbach, Danny, and Eirini Tatsi. 2018. Peer effects, free-riding and team diversity. Stockholm University.

Waldinger, Fabian. 2012. Peer effects in science: evidence from the dismissal of scientists in Nazi Germany. Review of Economic Studies 79, no. 2: 838-861. 
Figure 1

Average post-season probabilities by situation during game and season
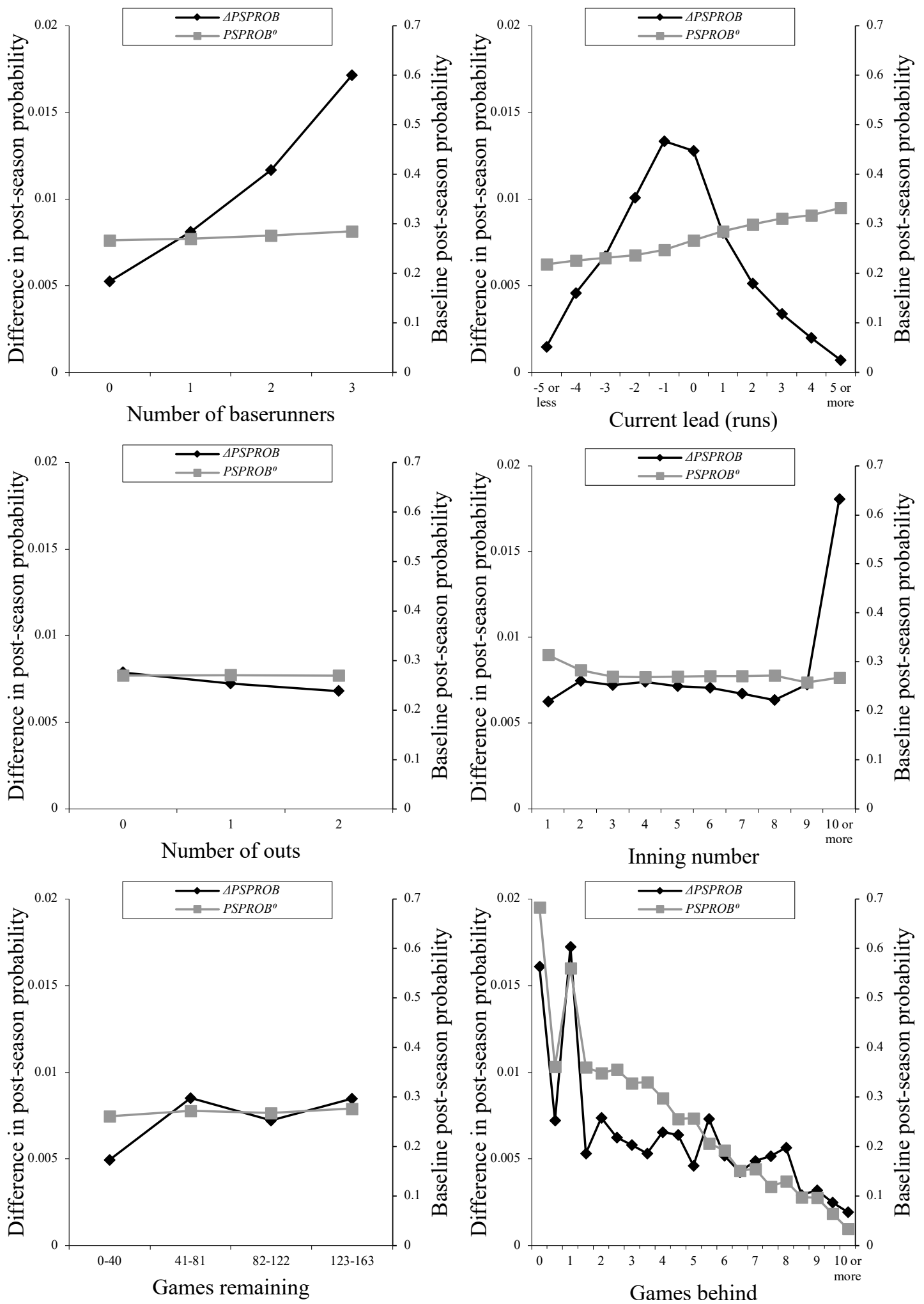
Figure 2

On-base coefficients by relative position of teammates

(a) Baseline post-season probability

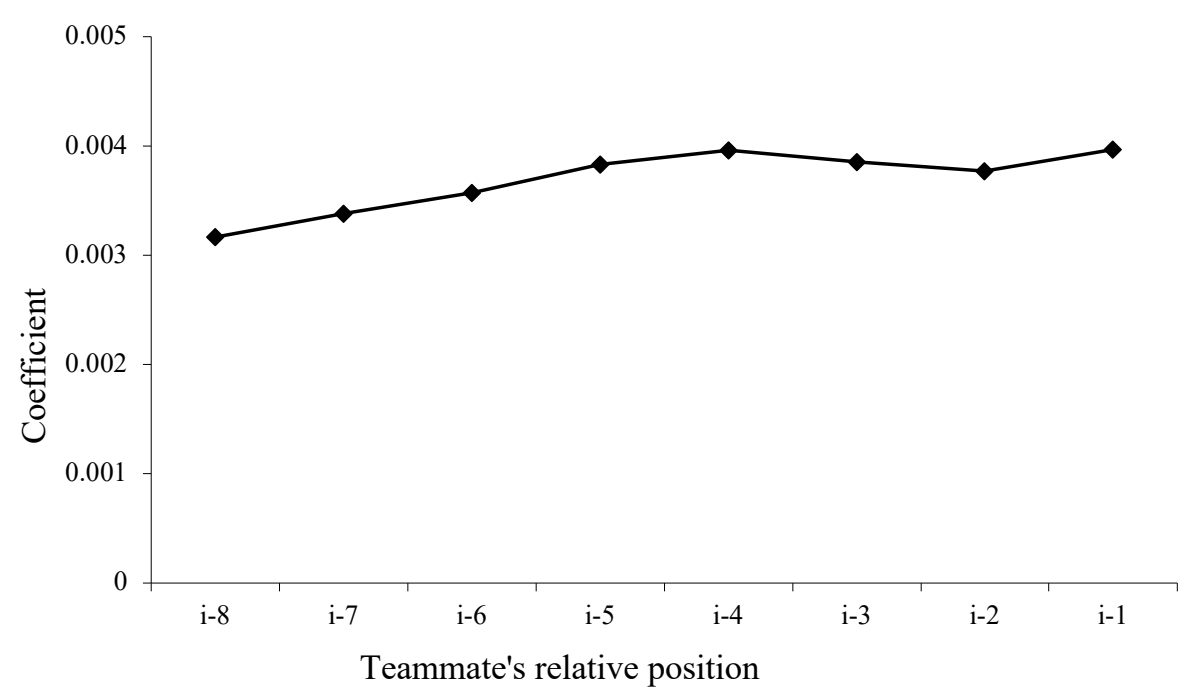

(b) Difference in post-season probability

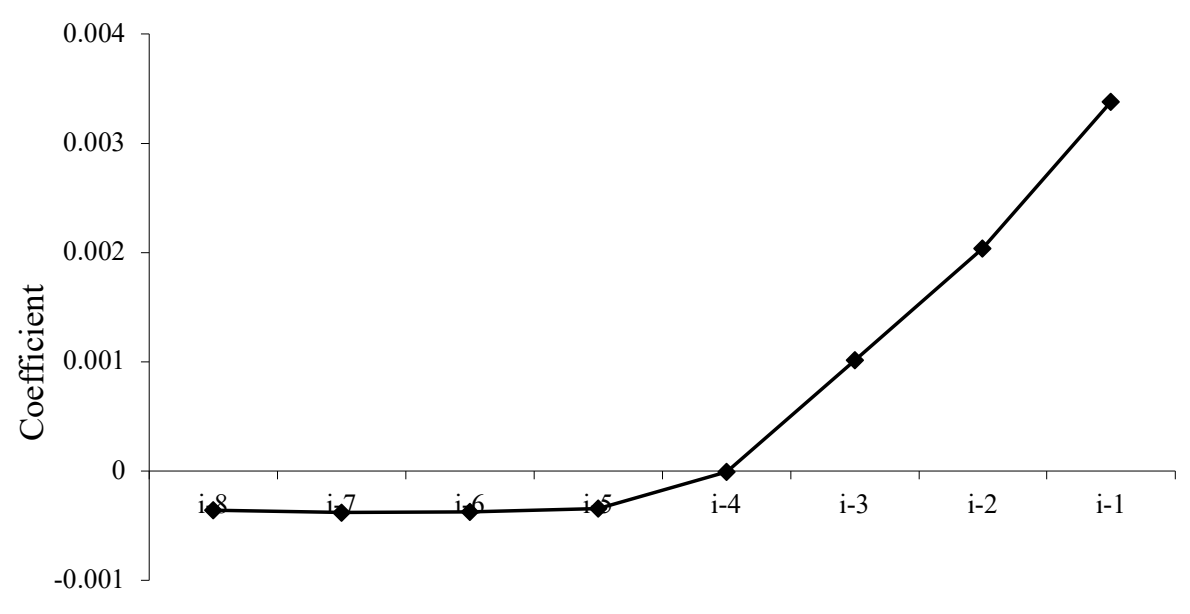

Teammate's relative position 
Table 1

Descriptive statistics

A. At-bat-level variables

\begin{tabular}{|c|c|c|c|c|}
\hline Variable & Mean & $\begin{array}{l}\text { Standard } \\
\text { deviation }\end{array}$ & Minimum & Maximum \\
\hline On base & 0.339 & 0.473 & 0 & 1 \\
\hline $\begin{array}{l}\text { Difference in hitter's post-season } \\
\text { probability }(\triangle P S P R O B)\end{array}$ & 0.007 & 0.013 & -0.107 & 0.324 \\
\hline $\begin{array}{l}\text { Hitter's baseline post-season probability } \\
\left(P S P R O B^{0}\right)\end{array}$ & 0.270 & 0.244 & 0.015 & 0.999 \\
\hline $\begin{array}{l}\text { Difference in pitcher's post-season } \\
\text { probability }\end{array}$ & 0.007 & 0.013 & -0.130 & 0.333 \\
\hline Pitcher's baseline post-season probability & 0.269 & 0.246 & 0.015 & 1.000 \\
\hline Inning 1 & 0.001 & 0.029 & 0 & 1 \\
\hline Inning 2 & 0.034 & 0.181 & 0 & 1 \\
\hline Inning 3 & 0.126 & 0.332 & 0 & 1 \\
\hline Inning 4 & 0.142 & 0.349 & 0 & 1 \\
\hline Inning 5 & 0.141 & 0.349 & 0 & 1 \\
\hline Inning 6 & 0.143 & 0.350 & 0 & 1 \\
\hline Inning 7 & 0.142 & 0.349 & 0 & 1 \\
\hline Inning 8 & 0.141 & 0.348 & 0 & 1 \\
\hline Inning 9 & 0.106 & 0.308 & 0 & 1 \\
\hline Inning 10 or more & 0.024 & 0.154 & 0 & 1 \\
\hline
\end{tabular}

B. Year-level variables

\begin{tabular}{lcccc}
\hline Variable & Mean & $\begin{array}{c}\text { Standard } \\
\text { deviation }\end{array}$ & Minimum & Maximum \\
\hline Real salary (\$ millions) & 1.880 & 2.347 & 0.166 & 16.583 \\
Bonus & 0.303 & 0.460 & 0 & 1 \\
\hline Number of observations & \multicolumn{3}{c}{2,066} \\
\hline
\end{tabular}


Table 2

Results of regressions using annual data

\begin{tabular}{|c|c|c|c|c|}
\hline \multirow[t]{2}{*}{ Variable } & \multicolumn{2}{|c|}{ Batting average } & \multicolumn{2}{|c|}{ On base percentage } \\
\hline & $(1)$ & $(2)$ & $(3)$ & $(4)$ \\
\hline $\begin{array}{l}\text { Average batting average among } \\
\text { all teammates }\end{array}$ & $\begin{array}{c}0.134 * * * \\
(0.034)\end{array}$ & & & \\
\hline $\begin{array}{l}\text { Average on base percentage } \\
\text { among all teammates }\end{array}$ & & $\begin{array}{c}0.077 * * * \\
(0.028)\end{array}$ & $\begin{array}{l}0.062 * * \\
(0.032)\end{array}$ & \\
\hline $\begin{array}{l}\text { Average fraction of those in line- } \\
\text { up on base }\end{array}$ & & & & $\begin{array}{c}0.028 \\
(0.024)\end{array}$ \\
\hline R-squared & 0.628 & 0.628 & 0.698 & 0.676 \\
\hline Number of observations & 15,257 & 15,257 & 15,257 & 11,489 \\
\hline
\end{tabular}

Notes: All models also include player dummies, team dummies and year dummies. In columns (1) and (2), observations are weighted by a player's number of atbats in a year; in columns (3) and (4), observations are weighted by a player's number of plate appearances in a year.

Standard errors are presented in parentheses. $* * *$ and $* * *$ denote significance at the $10 \%, 5 \%$ and $1 \%$ level, respectively. 
Table 3

Results of reduced form regressions for the probability of getting on base

\begin{tabular}{|c|c|c|c|}
\hline Variable & $(1)$ & $(2)$ & (3) \\
\hline Fraction of those in line-up on base & $\begin{array}{c}0.017 * * * \\
(0.002)\end{array}$ & $\begin{array}{c}0.024 * * * \\
(0.002)\end{array}$ & \\
\hline Player $i-1$ on base & & & $\begin{array}{c}0.001 \\
(0.001)\end{array}$ \\
\hline Player $i-2$ on base & & & $\begin{array}{c}0.009 * * * \\
(0.001)\end{array}$ \\
\hline Player $i-3$ on base & & & $\begin{array}{c}0.006 * * * \\
(0.001)\end{array}$ \\
\hline Player $i-4$ on base & & & $\begin{array}{c}0.002 * * \\
(0.001)\end{array}$ \\
\hline Player $i-5$ on base & & & $\begin{array}{c}0.003 * * * \\
(0.001)\end{array}$ \\
\hline Player $i-6$ on base & & & $\begin{array}{l}0.001 * \\
(0.001)\end{array}$ \\
\hline Player $i-7$ on base & & & $\begin{array}{c}-0.001 * \\
(0.001)\end{array}$ \\
\hline Player $i-8$ on base & & & $\begin{array}{c}0.003 * * * \\
(0.001)\end{array}$ \\
\hline Player fixed effects & Yes & No & No \\
\hline Player-game fixed effects & No & Yes & Yes \\
\hline R-squared & 0.015 & 0.353 & 0.353 \\
\hline Number of observations & $2,370,049$ & $2,370,049$ & $2,370,049$ \\
\hline
\end{tabular}

Notes: All models also include a full set of opposing pitcher dummies and innings dummies. Standard errors are presented in parentheses. $*$, ** and $* * *$ denote significance at the $10 \%, 5 \%$ and $1 \%$ level, respectively. 
Table 4

Results of regressions for baseline post-season probability

\begin{tabular}{|c|c|c|c|}
\hline Variable & $(1)$ & $(2)$ & (3) \\
\hline \multirow[t]{2}{*}{ Player $i-1$ on base } & $3.967 * * *$ & $2.281 * * *$ & $1.838 * * *$ \\
\hline & $(0.033)$ & $(0.071)$ & $(0.105)$ \\
\hline \multirow[t]{2}{*}{ Player $i-2$ on base } & $3.774 * * *$ & $1.295 * * *$ & $0.807 * * *$ \\
\hline & $(0.033)$ & $(0.071)$ & $(0.106)$ \\
\hline \multirow[t]{2}{*}{ Player $i-3$ on base } & $3.851 * * *$ & $0.880 * * *$ & $0.258 * *$ \\
\hline & $(0.033)$ & $(0.072)$ & $(0.108)$ \\
\hline \multirow[t]{2}{*}{ Player $i-4$ on base } & $3.962 * * *$ & $0.953 * * *$ & $0.247 * *$ \\
\hline & $(0.033)$ & $(0.072)$ & $(0.108)$ \\
\hline \multirow[t]{2}{*}{ Player $i-5$ on base } & $3.833 * * *$ & $0.882 * * *$ & 0.168 \\
\hline & $(0.033)$ & $(0.072)$ & $(0.108)$ \\
\hline \multirow[t]{2}{*}{ Player $i-6$ on base } & $3.574 * * *$ & $1.049 * * *$ & $0.311 * * *$ \\
\hline & $(0.033)$ & $(0.072)$ & $(0.107)$ \\
\hline \multirow[t]{2}{*}{ Player $i-7$ on base } & $3.378 * * *$ & $1.526 * * *$ & $0.895 * * *$ \\
\hline & $(0.033)$ & $(0.071)$ & $(0.106)$ \\
\hline \multirow[t]{2}{*}{ Player $i-8$ on base } & $3.166 * * *$ & $2.049 * * *$ & $1.411 * * *$ \\
\hline & $(0.033)$ & $(0.071)$ & $(0.105)$ \\
\hline Two-way interactions & No & Yes & Yes \\
\hline Three-way interactions & No & No & Yes \\
\hline R-squared & 0.991 & 0.991 & 0.991 \\
\hline Number of observations & $2,350,709$ & $2,350,709$ & $2,350,709$ \\
\hline
\end{tabular}

Notes: All coefficients and standard errors are multiplied a thousandfold.

All models also include a full set of innings dummies, batting order dummies, opposing pitcher dummies and team-game dummies. Standard errors are presented in parentheses. $*, * *$ and $* * *$ denote significance at the $10 \%, 5 \%$ and $1 \%$ level, respectively. 
Table 5

Results of regressions for difference in post-season probability

\begin{tabular}{lccc}
\hline Variable & $(1)$ & $(2)$ & $(3)$ \\
\hline Player $i-1$ on base & $3.381^{* * *}$ & $4.425^{* * *}$ & $3.365^{* * *}$ \\
Player $i-2$ on base & $(0.011)$ & $(0.024)$ & $(0.035)$ \\
& $2.040^{* * *}$ & $3.067 * * *$ & $2.110^{* * *}$ \\
Player $i-3$ on base & $(0.011)$ & $(0.024)$ & $(0.036)$ \\
& $1.013^{* * *}$ & $1.936^{* * *}$ & $0.994^{* * *}$ \\
Player $i-4$ on base & $(0.011)$ & $(0.024)$ & $(0.036)$ \\
& -0.009 & $0.431^{* * *}$ & $-0.309 * *$ \\
Player $i-5$ on base & $(0.011)$ & $(0.024)$ & $(0.036)$ \\
& $-0.346^{* * *}$ & $0.431 * * *$ & $-0.110^{* * *}$ \\
Player $i-6$ on base & $(0.011)$ & $(0.024)$ & $(0.036)$ \\
& $-0.377 * * *$ & $0.500 * * *$ & $0.161 * * *$ \\
Player $i-7$ on base & $(0.011)$ & $(0.024)$ & $(0.036)$ \\
& $-0.379 * * *$ & $0.212 * * *$ & $-0.182^{* * *}$ \\
Player $i-8$ on base & $(0.014)$ & $(0.024)$ & $(0.036)$ \\
& $-0.362^{* * *}$ & $0.129 * * *$ & $-0.064 *$ \\
Two-way interactions & $(0.011)$ & $(0.024)$ & $(0.035)$ \\
Three-way interactions & No & Yes & Yes \\
\hline R-squared & No & No & Yes \\
Number of observations & 0.627 & 0.628 & 0.629 \\
\hline
\end{tabular}

Notes: All coefficients and standard errors are multiplied a thousandfold.

All models also include a full set of innings dummies, batting order dummies, opposing pitcher dummies and team-game dummies. Standard errors are presented in parentheses. $*, * *$ and $* * *$ denote significance at the $10 \%, 5 \%$ and $1 \%$ level, respectively. 
Table 6

Results of regressions for the probability of getting on base

\begin{tabular}{|c|c|c|c|c|}
\hline Variable & $\begin{array}{l}\text { (1) } \\
\text { Full sample }\end{array}$ & $\begin{array}{l}\text { (2) } \\
\text { Hitters only }\end{array}$ & $\begin{array}{c}(3) \\
\text { No substitutes }\end{array}$ & $\begin{array}{c}\text { (4) } \\
\text { Probability of } \\
\text { a hit }\end{array}$ \\
\hline \multirow{2}{*}{$\begin{array}{l}\text { Difference in hitter's post- } \\
\text { season probability }(\triangle P S P R O B)\end{array}$} & $0.754 * * *$ & $0.774 * * *$ & $0.838 * * *$ & $0.531 * * *$ \\
\hline & $(0.053)$ & $(0.054)$ & $(0.067)$ & $(0.052)$ \\
\hline \multirow{2}{*}{$\begin{array}{l}\text { Hitter's baseline post-season } \\
\text { probability }\left(P S P R O B^{0}\right)\end{array}$} & $-0.786 * * *$ & $-0.789 * * *$ & $-0.886^{* * *}$ & $-0.806^{* * *}$ \\
\hline & $(0.017)$ & $(0.017)$ & $(0.020)$ & $(0.017)$ \\
\hline \multirow{2}{*}{$\begin{array}{l}\text { Difference in pitcher's post- } \\
\text { season probability }\end{array}$} & $-0.377 * * *$ & $-0.379 * * *$ & $-0.288 * * *$ & $-0.564 * * *$ \\
\hline & $(0.050)$ & $(0.051)$ & $(0.064)$ & $(0.049)$ \\
\hline \multirow{2}{*}{$\begin{array}{l}\text { Pitcher's baseline post-season } \\
\text { probability }\end{array}$} & $0.603 * * *$ & $0.604 * * *$ & $0.670 * * *$ & $0.610 * * *$ \\
\hline & $(0.016)$ & $(0.017)$ & $(0.020)$ & $(0.016)$ \\
\hline \multirow[t]{2}{*}{ Player $i-1$ on base } & $0.004 * * *$ & $0.006 * * *$ & $0.004 * * *$ & $0.006 * * *$ \\
\hline & $(0.001)$ & $(0.001)$ & $(0.001)$ & $(0.001)$ \\
\hline \multirow[t]{2}{*}{ Player $i-2$ on base } & $0.013 * * *$ & $0.013 * * *$ & $0.012 * * *$ & $0.005 * * *$ \\
\hline & $(0.001)$ & $(0.001)$ & $(0.001)$ & $(0.001)$ \\
\hline \multirow[t]{2}{*}{ Player $i-3$ on base } & $0.010 * * *$ & $0.010 * * *$ & $0.009 * * *$ & $0.005 * * *$ \\
\hline & $(0.001)$ & $(0.001)$ & $(0.001)$ & $(0.001)$ \\
\hline \multirow[t]{2}{*}{ Player $i-4$ on base } & $0.007 * * *$ & $0.007 * * *$ & $0.008 * * *$ & $0.007 * * *$ \\
\hline & $(0.001)$ & $(0.001)$ & $(0.001)$ & $(0.001)$ \\
\hline \multirow[t]{2}{*}{ Player $i-5$ on base } & $0.009 * * *$ & $0.009 * * *$ & $0.010 * * *$ & $0.008 * * *$ \\
\hline & $(0.001)$ & $(0.001)$ & $(0.001)$ & $(0.001)$ \\
\hline \multirow[t]{2}{*}{ Player $i-6$ on base } & $0.007 * * *$ & $0.007 * * *$ & $0.008 * * *$ & $0.007 * * *$ \\
\hline & $(0.001)$ & $(0.001)$ & $(0.001)$ & $(0.001)$ \\
\hline \multirow[t]{2}{*}{ Player $i-7$ on base } & $0.004 * * *$ & $0.004 * * *$ & $0.006 * * *$ & $0.005 * * *$ \\
\hline & $(0.001)$ & $(0.001)$ & $(0.001)$ & $(0.001)$ \\
\hline \multirow[t]{2}{*}{ Player $i-8$ on base } & $0.008 * * *$ & $0.008 * * *$ & $0.009 * * *$ & $0.007 * * *$ \\
\hline & $(0.001)$ & $(0.001)$ & $(0.001)$ & $(0.001)$ \\
\hline R-squared & 0.356 & 0.320 & 0.367 & 0.340 \\
\hline Number of observations & $2,335,789$ & $2,090,999$ & $1,790,912$ & $2,007,442$ \\
\hline
\end{tabular}

Notes: All models also include a full set of opposing pitcher dummies, innings dummies and player-game dummies. Standard errors are presented in parentheses. $* * *$ and $* * *$ denote significance at the $10 \%, 5 \%$ and $1 \%$ level, respectively. 
Table 7

Spillover elasticities by relative player position

\begin{tabular}{lcccc}
\hline Variable & $\begin{array}{c}\text { Elasticity of } \\
\text { complementarity } \\
\text { with player } i\end{array}$ & $\begin{array}{c}\text { Elasticity due to } \\
P S P R O B^{0} \\
(\times 1000)\end{array}$ & $\begin{array}{c}\text { Elasticity due to } \\
\Delta P S P R O B \\
(\times 1000)\end{array}$ & $\begin{array}{c}\text { Overall elasticity } \\
(\times 1000)\end{array}$ \\
\hline Player $i-1$ & $0.852^{* * *}$ & $-3.202^{* * *}$ & $2.616^{* * *}$ & $-0.586^{* * *}$ \\
Player $i-2$ & $0.541^{* * *}$ & $-3.033^{* * *}$ & $1.571^{* * *}$ & $-1.461^{* * *}$ \\
Player $i-3$ & $0.263^{* * *}$ & $-3.089^{* * *}$ & $0.779^{* * *}$ & $-2.309^{* * *}$ \\
Player $i-4$ & $-0.002^{* *}$ & $-3.186^{* * *}$ & $-0.007^{* *}$ & $-3.193^{* * *}$ \\
Player $i-5$ & $-0.090^{* * *}$ & $-3.091^{* * *}$ & $-0.267^{* * *}$ & $-3.358^{* * *}$ \\
Player $i-6$ & $-0.105^{* * *}$ & $-2.889^{* * *}$ & $-0.292^{* * *}$ & $-3.181^{* * *}$ \\
Player $i-7$ & $-0.112^{* * *}$ & $-2.732^{* * *}$ & $-0.294^{* * *}$ & $-3.026^{* * *}$ \\
Player $i-8$ & $-0.114^{* * *}$ & $-2.563^{* * *}$ & $-0.281^{* * *}$ & $-2.843^{* * *}$ \\
Teammate average & $0.168^{* * *}$ & $-23.785^{* * *}$ & $3.826^{* * *}$ & $-19.959^{* * *}$ \\
\hline Notes: *, ** and *** denote significance at the 10\%, 5\% and 1\% level, respectively, \\
\multicolumn{2}{c}{ and refer to standard errors obtained from a seemingly-unrelated regression. }
\end{tabular}


Table 8

Results of regressions for estimated on base coefficient

\begin{tabular}{lcc}
\hline Variable & $\Delta P S P R O B$ coefficient & $P S P R O B^{0}$ coefficient \\
\cline { 2 - 3 } & $(1)$ & $(2)$ \\
\hline Real salary (in \$ millions) & $-0.578^{*}$ & 0.064 \\
& $(0.310)$ & $(0.084)$ \\
Bonus & $-1.609^{* *}$ & 0.099 \\
& $(0.786)$ & $(0.277)$ \\
\hline R-squared & 0.547 & 0.473 \\
Number of observations & 2,066 & 2,066 \\
\hline
\end{tabular}

Notes: All models also include a full set of age dummies and person dummies.

The dependent variables are estimated coefficients from separate estimation of in the model in column (4) of Table 4 for each player-year combination. Only player-year combinations with more than 100 plate appearances are included. Bootstrapped standard errors (from 100 replications) are presented in parentheses. *, ** and $* * *$ denote significance at the $10 \%, 5 \%$ and $1 \%$ level, respectively. 